To cite this article: Julie A. Timmermans \& Kathryn A. Sutherland (2020) Wise academic development: learning from the 'failure' experiences of retired academic developers, International Journal for Academic Development, 25:1, 43-57,

DOI: 10.1080/1360144X.2019.1704291

To link to this article: https://doi.org/10.1080/1360144X.2019.1704291

\title{
Wise academic development: Learning from the 'failure' experiences of retired academic developers
}

\author{
Julie A. Timmermans ${ }^{a *}$ and Kathryn A. Sutherland ${ }^{b}$ \\ ${ }^{a}$ Higher Education Development Centre, University of Otago, Dunedin, New Zealand; \\ ${ }^{b}$ Centre for Academic Development, Victoria University of Wellington, Wellington, New \\ Zealand
}

Informed by Constructive Developmental Theory and the Threshold Concepts

Framework, we interviewed retired academic developers from four continents and asked them to describe their processes of learning from perceived failures and how they see the role of academic developers in supporting academics through failures. Findings regarding participants' definitions of failure, ways of making sense of and learning from failure, and recommendations for supporting academic colleagues' learning from failure are shared through tables, quotations, and poetry. Findings show that 'wise academic development' embraces curiosity about failure, integrates the (sometimes) transformative nature of failure, shares the load of sense-making, and cultivates connectedness.

*Julie A. Timmermans

Higher Education Development Centre

University of Otago

65 Union Place West

Dunedin, NEW ZEALAND 9016

Email: julie.timmermans@otago.ac.nz

Timmermans ORCID iD: 0000-0003-2814-8106

Sutherland ORICD iD: 0000-0002-2629-7880 


\title{
Wise academic development: Learning from the 'failure' experiences of retired academic developers
}

\author{
Informed by Constructive Developmental Theory and the Threshold Concepts \\ Framework, we interviewed retired academic developers from four continents \\ and asked them to describe their processes of learning from perceived failures \\ and how they see the role of academic developers in supporting academics \\ through failures. Findings regarding participants' definitions of failure, ways of \\ making sense of and learning from failure, and recommendations for supporting \\ academic colleagues' learning from failure are shared through tables, quotations, \\ and poetry. Findings show that 'wise academic development' embraces curiosity \\ about failure, integrates the (sometimes) transformative nature of failure, shares \\ the load of sense-making, and cultivates connectedness.
}

Keywords: failure, learning, threshold concepts

\section{Background and rationale}

'I thought I was the only one.'

It was both piercing and soul-strengthening for Julie to hear these words spoken by a colleague who had carried with her, perhaps for many years, the idea that she was alone in her experience of failure in teaching. Sharing her story with a group of compassionate colleagues in a workshop at a teaching and learning conference, this colleague had realised that she, indeed, was not the only one who felt she had failed to reach her students. As academic developers, we've likely all heard a similar story. Over 25 years ago, Shulman (1993) coined the phrase 'pedagogical solitude' referring to the individuality and loneliness of teaching. It appears, too, that there is a very real solitude of failure - of closing both literal and metaphorical doors to keep out - what? Looks and words of disappointment and anger, feelings of shame and guilt? Solitude of this kind does not bring connection. So, we seek another way that involves opening those doors, sharing stories, and building connection. 
The need to discuss failure more openly in academia and beyond has certainly come to light in recent years (Parkes, 2019; Stefan, 2010). 'Failed' research experiments (with 'null' results) are rarely published, creating bias toward positive results and missed opportunities for learning (Franco, Malhotra, \& Simonovits, 2014). The personal costs of hiding failure are also high. Sharing only our "narratives of success ... renders our setbacks invisible both to ourselves and to others' (Stefan, 2010, p. 467). Failure is individualised and privatised (Gill, 2010). We are called to develop resilience - a quality enabling us to withstand the impact of failures and to persevere. However, the burden of overcoming failure is a solitary pursuit and responsibility. We are not further connected to and lifted up by the communities and cultures in which we work. We are not reassured that failure is a normal dimension of being human.

Stories of failure are powerful and intriguing. Increasingly, people are sharing their stories through initiatives such as the 'Stanford Resilience Project', 'CVs of failure' and 'rejection walls'. Conferences are also dedicated to the topic of failure (e.g., FailCon). We wish to bring the analysis of failure into the realm of research on academic development. As academic developers, we are fundamentally interested in the process of learning. Consequently, through our current research, we are deeply interested in documenting accounts of the cognitive, emotional, and identity-shaping labour involved in making meaning of failure - accounts probing beyond 'I failed, but eventually, it all worked out'. To elicit these accounts, we draw on two frameworks that are consistent with our constructivist roots and that acknowledge the holistic nature of learning. We describe these in the upcoming 'Theoretical Framework'.

Before proceeding, however, we pause to express our deep gratitude to our participants. As the title illustrates, study participants were retired academic developers. We often hear lamentations about selfishness in academia, but our experience in approaching our retired 
colleagues is that academic generosity is abundant. In many cultures, elders are turned to for their wisdom - for counsel on important matters facing individuals, families, and communities (cf Stielgelbauer, 1996). We wondered what we might learn from the 'elders' of the academic development community about how to work wisely. In this article, we seek to share wisdom that retired colleagues have developed through constructing meaning from their own experiences of failure. We share not only what they have learned, but how they have learned. We do this, so that their knowledge and processes might be integrated into our ways of thinking, practising, and being as we support individuals and our institutions. Wisdom does not come from ageing. Failure does not lead to wisdom; however, it can, if we learn from it.

\section{Theoretical framework}

Two assumptions underpin our work. First, we believe that, as individuals, we seek to be integrated, to be whole (e.g., Erikson, 1993). Second, as humans, we are interconnected. As academic developers, a fundamental aspect of our work is to connect people and knowledge across disciplines and across the university (see Sutherland, 2018a and Timmermans, 2014).

Our work's theoretical underpinnings are deeply constructivist, with two key frameworks informing data collection and analysis. In seeking to understand how colleagues learn from failure, we adopt the conception that learning is an active process of meaning-making (e.g., Anderson \& Krathwohl, 2001; Kegan, 1982) and is often characterised as a developmental process. Kegan's (1982) Constructive-Developmental Theory of Meaning-Making weaves together meaning-making and development and advances that, throughout our lifetimes, our abilities to construct meaning evolve through regular periods of stability and change. As our capacity to make meaning expands, we 
become increasingly capable of reflecting on what we were once embedded in. Kegan's theory (1982) also honours the 'equal dignity' of affect in the learning process (p. 107) and draws our attention to the emotional dimension of our participants' experiences.

We also adopt the lens of the Threshold Concepts Framework (TCF) (Meyer \& Land, 2003). Although the idea of threshold concepts is somewhat contested (e.g., Salwén, 2019), over almost two decades, the TCF has generated a bountiful body of scholarship across disciplines (Flanagan, 2019) and has provided a powerful lens for understanding learning from the learners' perspective. As the one non-negotiable feature of a threshold concept is its transformative ability (Land, 2016), we look in our data for potentially transformative shifts in cognition, affect, and identity that may occur as a result of grasping a threshold concept - a transformative insight related to failure and/or learning from failure. While we do not assume a priori that learning from failure has the qualities of a transformative learning experience, we are nonetheless curious as to whether or not it may. We listen and probe for the ways in which participants have (re)constructed meaning of their experiences and how they describe the 'liminal,' emotional spaces (e.g., Rattray, 2016) between constructions.

At their roots, both frameworks are deeply constructivist: learning and meaning are created by the learner. Each also honours the 'equal dignity' of affect in making meaning and sense of experience. Affect is not peripheral but integral to the learning process. Finally, both pay deep attention not only to the outcomes, but also to the process of learning. This attention to construction, transformation, emotion, and process seems especially well-suited to examining how people learn from failure.

\section{Research questions}

The following research questions guided our work:

- What experiences do retired academic developers identify as failures in their 
careers?

- How did they make sense of and learn from these experiences?

- How do they see the role of academic developers in working with academic staff to deal with challenges and failures?

\section{Methodology}

\section{Data collection}

\section{Participant selection}

Pilot interviews with non-retired, but senior academics and academic developers revealed that time appears crucial in how people make sense of experiences. Reactions and insights unfold, oftentimes over years. We reasoned that retired colleagues were likely to identify an event from the not-too-recent past, which would give insight into the learning process. We suspected, too, that perspective might be important - retired colleagues put career events into broader and longer contexts of other life events; perhaps this framing, too, could be helpful to earlier career colleagues.

A profound motivation for interviewing retired academic developers was to connect us further in our human experiences. Our retired colleagues have had long and successful careers; they have been leaders; they are well-regarded. Asking them to share experiences perceived, perhaps, as failures could help others to see that career paths are not always made up only of successes, and that one can have a rich career even with (or because of) these unexpected failures and the opportunities for learning they present.

There were also storytelling and 'legacy' elements to our participant selection. Elders are the holders of their people's stories. Capturing the voices of colleagues who have shaped our field allows their wisdom to endure and be integrated into our work. We therefore approached retired academic developers we know and admire, then used 
snowball sampling to request recommendations for other interviewees to broaden geographical coverage. We conducted individual interviews with eight retired academic developers (four men, four women) from four continents, who had worked as academic developers in over 16 countries. We do not share demographic information (i.e., nationalities, age, specific countries worked in) in order to protect the identities of our colleagues, some of whom shared deeply personal experiences. The research received ethics approval from the University of Otago.

\section{Interview protocol}

The semi-structured interviews lasted between one and three hours. Questions, informed by the frameworks described above, elicited participants' stories of failure, how they made sense of failure, lessons learned, and suggestions for supporting others. We did not probe specifically for 'threshold concepts', or inquire as to whether any of the experiences were 'transformative', preferring instead to let this emerge.

\section{Data analysis}

Having recorded and transcribed the interviews, we took an inductive thematic approach to analysis (cf Braun \& Clarke, 2006), reading each transcript and noting key themes that emerged for each participant. Both authors first read all transcripts separately. Then, we came together to agree upon key themes through thorough re-reading, comparing, challenging and negotiating. The themes that stood out most clearly (i.e., more than a third of participants made comments relating to these themes) included the following: definitions of failure, stories of and responses to failure, emotions surrounding failure, and how people make sense of and look back on perceived failures. We then used the research questions above to look across all eight transcripts for common and contrasting themes in relation to experiences of failure and how academic developers might support 
others in coping with failure. Finally, we searched for key terms indicative of potential threshold concepts, including for example: threshold, transform, adapt, evolve, recognise, realise, epiphany.

\section{Findings}

We begin by defining failure from the participants' perspectives and examining their failure stories, along with the range of emotions expressed as they grappled with failure. We then convey the strategies participants used to make sense of their experiences. Lastly, we offer suggestions for ways academic developers might support academic colleagues to make sense of their own failures.

We take several approaches to presenting our findings, from poetry to tables to sample quotations, and we explain each approach as it occurs. To protect identities, we use pseudonyms.

\section{How retired academic developers define failure}

Participants' constructions of failure varied widely. Stories were detailed, and, sometimes, dramatic. For some participants, the very idea of 'failure' is non-existent; some even refused to use the term, referring instead to 'detours' or 'learning opportunities'. For others, failure is significant, and conceptualised very specifically. In the poem below, we have crafted our interviewees' words into a symphonic definition of failure. The phrases are all excerpted from the transcripts directly, and all eight participants' voices are represented:

\section{Failure}

Failure is somehow so damning and so final. I cannot help.

I am incompetent. I cannot resolve this. 
Things have not worked out the way I would have wanted.

I have not achieved the goals I set for myself.

There are mistakes, there are detours.

I must stay.

I must leave.

Failure arises when I do not seize the opportunity to learn when I do not start again

when my heart and mind are not open to change

when I feel that I have compromised my identity and integrity.

But whose failure is this? Have I failed, or have I been failed?

Failure does not necessarily mean that I have done anything wrong.

\section{Failure stories}

Participants recounted stories that happened 10-15 years ago. They ranged from stories about leadership failures, to programmes that never got off the ground or expanded too quickly, to centre closures, to the breakdown of professional relationships. For some participants, qualifying an experience as a failure stemmed from a belief that one had compromised one's values, identity, or integrity. We present a conglomeration of the stories in Table 1, in order from most to least frequently described.

\section{[Insert Table 1 near here]}

Some readers may recognise situations from their own experience in these examples. For others, especially those not (yet) in senior or management roles, these circumstances may not be as familiar. Unsurprising to anyone, though, is how each situation was imbued with emotion.

As researchers, we could not listen to these stories without being affected. We were humbled, heart-broken, and inspired. The emotional resonance of 'failure' came through strongly in every transcript, but the emotions differed for each interviewee. We capture some of these emotions in the poem below, again composed from the words of all interviewees. 


\section{Emotional Wisdom}

People are very scared of the word failure It exposes you.

It makes you feel frustrated, troubled, mad, uncomfortable, disappointed, confused.

I felt outgunned, inexpert, vulnerable, disheartened, and angry.

They made me feel undermined, belittled, shunted off, neutered, skewered, squeezed so tight, squashed inside.

You're always rather vulnerable as academic developers, aren't you?

He broke down in tears: 'What have I done wrong?'

She cried for two weeks.

They were humiliated.

But you just have to keep coming back; it's tenacity, it's realistic optimism.

Every problem is not a crisis.

By Wednesday, the programme on Tuesday will be finished, and life will go on.

And compulsion isn't a good starting point for academic development. When you start with compulsion, you've got a lot of ground to make up before you can begin to work positively with people. It requires their trust in you.

When I look at the educational developers I've admired the most, they're always the people who appear very calm - whether they are or not, they appear that way.

And because they're calm,

then the people who work for them are calm, and the work gets done.

And those people, when things don't go right, they don't remain crushed by it.

Instead, over time, they say

It actually opened up doors that I wouldn't have had before and

I'm a lot more grateful for that experience than I was at the time and

If you are gloomy and saying, 'this will never happen' well, it probably won't! and 
I don't regret anything; it's all part of the rich learning journey

But it takes courage to see that this is a

long journey, not a short one.

Patience and tolerance, I think,

should be the hallmark

of the academic developer.

\section{Making sense of, and learning from, failure}

As the poem demonstrates, some participants considered these moments as 'devastating' failures when they happened, but not now; others still carry the scars of failure; and some never framed their experiences as failure. Other experiences were, at times and over time, infused with positivity. Participants actively worked to learn from, cope with, and make meaning of their experiences by employing the following strategies:

\section{Taking deliberate action}

All participants were driven to act to handle and make sense of their situations; none appeared to employ the 'ignore and hope it will go away' strategy. Actions included strategising and prioritising; pushing things up to senior levels; building one's own and one's staff's leadership capacity; and starting initiatives, such as new workshops or programmes.

\section{Seeking advice, help, or different perspectives}

Participants discussed ways in which they sought help to manage and make sense of failure. These included seeking professional counselling or coaching, bringing in external expertise, conversing with others, and adopting an empathetic position by 'standing in the other person's shoes' to understand the situation from their perspective. They stressed the importance of surrounding oneself with trusted people who would provide honest feedback and help one gain (an alternative) perspective on the situation. For example, the participant whose failure situation related to a breakdown in a professional relationship 
found it helpful to get a trusted colleague's perspective:

You need your own little tight network. People who will, not just soothe you when things go wrong, but ask tough questions... and help you get perspective and embolden you to take the next step....once I talked it out with her...I felt a lot more courageous about dealing with this because she helped get things in perspective. She gave me confidence that, yeah, we're going to get this done, it's just not going to be pretty. (Rosa)

\section{Investing less or leaving the situation}

In order to maintain a sense of personal integrity, several participants had to retreat from the situation and in some cases, from their universities entirely:

I just thought, well I don't want to work in this kind of environment, I will move on. But that came at a cost. I did feel in this sense, the failure. (Lorenzo)

Others described the importance of being willing to let go - of projects, ways of working, ego, and future plans:

I had to be willing to say, 'You've fought the good fight, you've done what you can do. Let it go and see if somebody else can come at this problem' [trying to implement a new technology across the university]. (Eliza)

One of the things I felt most devastated by was that I had mapped my career; I saw myself moving up into [senior learning and teaching] roles and the path was very clear to me: do my time there, build the innovation, get the evidence, move on. And that door was closed.' (Dinah)

\section{Trying to understand the causal factors}

Participants attempted to deconstruct the factors that may have contributed to the perceived failures. For example, a participant who was trying to bring in a new, national, academic development programme noted the following: 
Every stage there was failure, and again you reconceptualise it to think, what are the... factors which lead to failure...you've got to drill down and see what's the cause of that. Is it something worthwhile handling, or not? (Edward)

Another, whose academic development unit was restructured against his and his colleagues' wishes, was wistfully philosophical in retrospect:

A way of rationalising it later is, sometimes you just get caught in these historic changes, and different currents come in and you just can't swim against them, you've just got to take it on the chin, take a deep breath, and move on. (Lorenzo)

\section{Failure as a threshold concept and threshold concepts in failure}

While we did not intentionally probe for threshold concepts, three powerful insights emerged. First, the experience of failure itself is, for some, a transformative event in helping become more fully oneself. Second, in some instances, the process of making sense of failure revealed transformative lessons. Third, failure experiences may trigger transformative insights about the nature and purpose of academic development work.

For four of the eight participants, the failure experience created a qualitative shift in ways of thinking, being, or identity. This seemed especially true when the failure experience violated their values, identity, or integrity.

It really forced me to sit down and work out what I stood for and what was important to me...That was a turning point in my entire career and life...when this identity, this person became strong and evident... Luckily I had the capacity to learn and grow from it. (Dinah)

Participants also identified several transformative insights in learning from failure that they could apply to future experiences.

[Now] I'm not going to do something that I don't think is appropriate...I'm much more likely to speak up and challenge... I'm much more willing to express opinions which may be a very minority opinion (Gerald) 
[At a later] job interview I talked about how I didn't tolerate bullying, how I would stand up for what was right and appropriate. (Dinah)

They also recognised their own limitations:

Life never stands still, it's always changing, we always have to adapt or sometimes transform ourselves in response to those changes...it's really about recognising what's happening, and for me I was caught up in this [situation] and I didn't stop to think about the bigger picture of it. (Rosa)

It made me aware, at that point, of my own managerial capacity...that proper management is the most difficult part of - well for me - an academic position. (Lorenzo)

At times, insights led to a different construction of failure.

It just changed the direction and confidence in my work and so forth. It actually opened up doors that I wouldn't've had before... it wasn't a failure it was an awakening. (Gerald)

I think it was really maturation...I really felt that I'd been forged. (Dinah)

For some participants, the failure appeared to instigate a qualitative shift in ways of seeing academic development work. This learning could then be integrated into future academic development practice. The following are two key findings:

Academic development and academic developers need to become more intentionally strategic:

It actually taught me that I had to become far more strategic about what I was doing and how I played the game. And without that, I would've just muddled on and I would've been good-ish at it, but I don't think I would've built the excellence that I did after. (Dinah)

Academic developers must recognise the importance of senior leadership influence: 
That was my threshold moment, really understanding the scope of my work, that I needed to be in that larger arena... my epiphany was that we needed to be more than good citizens in the university, we had to become a formal part of the leadership structure. (Rosa)

'We're expecting you people at the frontline to deliver it...it doesn't really matter how you do it, just do it and don't screw up, but if you do screw up, we'll blame you.' So that was a kind of salutary experience too...[It] taught me that in middle management you can be quite vulnerable. (Lorenzo)

We intend to explore this insight about the role of academic developers in university leadership structures in a future paper. For now, we turn to the wisdom we gleaned about supporting academics when they encounter failure.

\section{Supporting academics with their failure experiences}

In Table 2, we outline eight key strategies that our retired colleagues report having used to support academic colleagues' experiences of failure. We offer these as examples of 'wise academic development' in action. Each strategy is accompanied by an explanation of the kinds of processes employed or actions taken, as well as supporting quotations. We list the recommendations in descending order of the number of participants who mentioned each strategy. It would be interesting for future research to explore how common such strategies are across a bigger pool of academic developers.

\section{[Insert Table 2 near here]}

\section{Discussion}

Our interviews reveal that failure is clearly a personal construction. What one person may perceive as failure, another may not. Participants' stories led us to question where the construction of experiences as failure originates. Is it internal to the individual (i.e., do I, but not necessarily others, see it as failure), or external (i.e., I do not see this as a failure, 
but others do)? This interpretation of failure as a personal construction also stems from findings that some participants' failure experiences are clearly tied to feelings of compromised values, identity, and/or sense of integrity. Such 'betrayals of self' (Brown 2015) appear to threaten one's sense of identity, integrity, and wholeness (Erikson, 1993).

Unsurprisingly, the experience of failure, whether tied to identity and values, or not, often propelled participants into a tumultuous 'liminal space' (cf Meyer \& Land, 2005; Rattray, 2016), a 'messy middle' (Brown, 2015) of sense-making. This sense-making was multi-dimensional and involved constructing meaning not only cognitively (through reframing and reconceptualising, for example), but equally grappling with one's emotions.

While one might imagine that emotions experienced in relation to failure might be 'negative' ones, our data reveal a more nuanced depiction. Certainly, there was deep disappointment, sadness, and, at times, seemingly trauma. And yet, there was also optimism and hope. Some participants learned to navigate emotional dichotomies and oscillations. The richness of the meaning-making space underscores that time is central to our understanding of this process. Often, (re)constructing meaning, emotions, and identity from one's failure experiences was the fruit of years of work. Over time, participants constructed and integrated into future situations many lessons. Such learning from failure is common and encouraging (cf Brown 2015), but not always easy.

An important compendium of lessons learned appeared to focus on the importance of self and others. Clarifying one's identity, working from a place of integrity, and developing awareness of one's capabilities grew within participants the courage, resilience, and confidence to face future situations, and to answer and stand with more certainty and 'presence' (Cuddy, 2015) in the face of such questions as 'Who am I, and what do I stand for'? 
Surrounding oneself with trusted others able to offer new perspectives was also crucial. This points to a role we may have as academic developers in supporting academic staff with making sense of the challenges and failures they experience. The current discourse is that academics' wellbeing is compromised (Gill, 2010; Salimzadeh, Saroyan, \& Hall, 2017). We are deeply concerned, along with other academic developers worldwide, in moving towards a more holistic approach to supporting the 'whole academic' (Sutherland, 2018b). Moving away from the individualisation and privatisation of anxiety and feelings of failure (Gill, 2010) by normalising the sharing of failure stories may be one of the simplest ways to 'mitigate malicious envy' (Huang et al., 2018) making us seem more human in the eyes of others, thereby connecting us to our colleagues. Sharing successes and failures will surely help to foster collegiality and connectedness within our institutions, thereby contributing to wellbeing. How do we, as academic developers create welcoming spaces for people to tell their stories of failure? Our retired academic development colleagues imply, as Table 2 shows, that empathy, closeness, trust, and conversation are all needed. We must also acknowledge the complexity of failure and help our colleagues to break that complexity down by getting perspective and seeing other views.

As academic developers, we are uniquely situated to serve our academic colleagues and our institutions. Our concern for supporting the whole academic can perhaps fuel the courage needed to explore the role that academic developers may have in supporting institutional leaders to respond to failure in ways that nurture learning. One of academic developers' core ways of knowing and being is 'understanding and working at multiple levels of the system to influence positive culture change' (Timmermans, 2014). Such concern for promoting the wellbeing of individuals and institutions can compel us to work to shift our institutions' cultures to help cultivate connectedness, wholeness, and 
wellbeing. Ultimately, we would like for failure to be acknowledged as part of our human experience and for discussions about it to become less hidden within our institutions.

\section{Concluding thoughts}

As with any project, we leave with insights and many questions. Success is not the absence of failure. One can learn from an experience of failure and yet still perceive it as a failure. We do not suggest that knowing others' experiences of failure will safeguard us from experiencing our own. In fact, we do not want to deprive ourselves of these experiences. Our hope, however, is that the wisdom of our retired academic developer colleagues may guide us to navigate these tumultuous spaces, while providing reassurance that we are not alone. As academic developers, we wish to model and foster a culture of learning from failure, and to help people to become curious about their failures. Ultimately, we may choose to integrate the wisdom of our colleagues, so that we may practise academic development more wisely.

\section{Notes on contributors}

Julie A. Timmermans is a Senior Lecturer in the Higher Education Development Centre at the University of Otago. She is grateful for the many wise academic developers who have been her teachers and mentors.

Kathryn A. Sutherland has worked in academic development at Victoria University of Wellington of New Zealand for 20 years, but she is still learning what it means to do academic development wisely. 
References

Anderson, L.W., \& Krathwohl, D. (Eds.). (2001). A taxonomy for learning, teaching, and assessing: A revision of Bloom's taxonomy of educational objectives. New York, NY:Longman.

Braun, V., \& Clarke, V. (2006). Using thematic analysis in psychology, Qualitative Research in Psychology, 3(2), 77-101. https://doi.org/10.1191/1478088706qp063oa

Brown, B. (2015). Rising strong: The reckoning. The rumble. The revolution. New York, NY: Spiegel \& Grau.

Cuddy, A. (2015). Presence: Bringing your boldest self to your biggest challenges. New York, NY:Little, Brown \& Company.

Erikson, E. (1993). Childhood and society. New York/London: W.W. Norton \& Company.

Flanagan, M. T. (2019). Threshold concepts: Undergraduate teaching, postgraduate training, professional development and school education: A short introduction and a bibliography. Retrieved from https://www.ee.ucl.ac.uk/ mflanaga/thresholds.html

Franco, A, Malhotra, N., \& Simonovits, G. (2014). Publication bias in the social sciences: Unlocking the file drawer. Science, 345(6203), 1502-1505. doi:10.1126/science. 1255484

Gill, R. (2010). Breaking the silence: The hidden injuries of neo-liberal academia. In R. Ryan-Flood \& R. Gill (Eds.), Secrecy and silence in the research process: Feminist reflections. Abingdon/New York:Routledge.

Huang, K., Brooks, A.W., Buell, R.W., Hall, B., \& Huang, L. (2018). Mitigating malicious envy: Why successful individuals should reveal their failures. Harvard Business Review, Working paper 18-080. Retrieved from 
https://www.hbs.edu/faculty/Publication\%20Files/18-080_56688b05-34cd-47efadeb-aa7050b93452.pdf

Kegan, R. (1982). The evolving self: Problem and process in human development. Cambridge, MA:Harvard University Press.

Land, R. (2016). Toil and trouble: Threshold concepts as a pedagogy of uncertainty. In R. Land, J.H.F. Meyer, \& M.T. Flanagan (Eds.), Threshold concepts in practice (pp. 11-24). Rotterdam/Boston/Taipei:Sense.

Meyer, J.H.F., \& Land, R. (2003). Threshold concepts and troublesome knowledge: Linkages to ways of thinking and practising within the disciplines. In C. Rust (Ed.), Improving student learning: Improving student learning theory and practice-10 years on (pp. 412-424). Oxford, UK:Oxford Centre for Staff and Learning Development.

Meyer, J.H.F., \& Land, R. (2005). Threshold concepts and troublesome knowledge (2): Epistemological considerations and a conceptual framework for teaching and learning. Higher Education, 49(3), 373-388.

https://doi.org/10.1007/s10734-004-6779-5

Parkes, E. (2019, January). Scientific progress is built on failure. Nature. Retrieved from: https://www.nature.com/articles/d41586-019-00107-y. doi:10.1038/d41586-019-00107-y.

Rattray, J. (2016). Affective dimensions of liminality. In R. Land, J.H.F. Meyer, \& M. T. Flanagan (Eds.), Threshold concepts in practice (pp. 67-76). Rotterdam/Boston/Taipei:Sense.

Salimzadeh, R., Saroyan, A., \& Hall, N.C. (2017). Examining the factors impacting academics' psychological well-being: A review of research. International Education Research, 5(1), 13-44. http://dx.doi.org/10.12735/ier.v5n1p13 
Salwén, H. (2019): Threshold concepts, obstacles or scientific dead ends? Teaching in Higher Education. https://doi.org/10.1080/13562517.2019.1632828

Shulman, L.S. (1993). Forum: Teaching as Community Property: Putting an end to pedagogical solitude. Change: The Magazine of Higher Learning, 25(6), 6-7. https://doi.org/10.1080/00091383.1993.9938465

Stefan, M. (2010). A CV of Failures. Nature, 468, 467. doi:10.1038/nj7322-467a

Stielgelbauer, S.M. (1996). What is an elder? What do elders do? The Canadian Journal of Native Studies, 16(1), 37-66. Retrieved from http://www3.brandonu.ca/cjns/16.1/Stiegelbauer.pdf

Sutherland, K.A. (2018a). Cultivating connectedness and generosity in universities: A view of early career academic experience in Aotearoa, New Zealand. On Education. Journal for Research and Debate, 1(3). https://doi.org/10.17899/on_ed.2018.3.8

Sutherland, K.A. (2018b). Holistic academic development: Is it time to think more broadly about the academic development project? International Journal for Academic Development, 23(4), 261-273. https://doi.org/10.1080/1360144X.2018.1524571

Timmermans, J.A. (2014). Identifying threshold concepts in the careers of educational developers. International Journal for Academic Development, 19, 305317. doi:10.1080/1360144X.2014.895731 